\title{
An exploration of the motivations of service users and carers involved in student social work education and the challenges that such involvement brings
}

\author{
Valerie Gant, Edge Hill University
}

\begin{abstract}
Since the inception in 2003 of the degree-based route for social work qualification, the General Social Care Council (GSCC) requires people who use social work services and carers to become involved in all aspects of a learners experience on qualifying social work programmes. This article reports on a qualitative study designed to explore the motivations and challenges such involvement brings. The aim was to incorporate the voices of those involved and add to the discourse on user and carer involvement in higher education. A series of focus groups occurred to investigate differing perspectives. Views from all parties regarding the learner experience were explored. Findings suggest that students had much to gain in terms of confidence and skills by involvement by users and carers from theoretical and practical perspectives. Service users and carers reported they enjoyed the experience and for some this also lead to an increase in confidence and abilities. Academic staff reported how the involvement of service users and carers brought value and 'reality' to classroom based learning. In conclusion, moving beyond the boundaries of 'traditional' classroom based learning, towards the myriad of possibilities user and carer involvement in the curriculum brings, enhances the experience of learners, academics, users and carers alike.
\end{abstract}

Keywords: Service user and carer involvement; higher education; social work.

\section{Introduction}

With the onset in 2003 of the new degree in social work, came the requirement from the Department of Health (DoH, 2002) that higher education institutions (HEIs) offering such a degree needed to involve people who are the recipients of social work services, and their carers. Funding was provided by the GSCC to attain this involvement which was required in several key areas including design of the course, student selection, teaching and assessment. It is at the discretion of each individual institution how this funding is allocated. At the HEI under exploration, individual service users and carers as well as service user and carer organizations are encouraged and supported to become involved and receive payment for such involvement. There has been much written about the perspectives and experiences of those involved (Ager et $a l ., 2005$. Doel \& Best, 2008, Levin, 2004) however motivating factors, challenges faced and the link between this and the learner experience has received scant attention in the literature.

This paper reports on a small scale research study which took place in one English HEI during late 2011/early 2012. Qualitative research methods utilising focus group discussions were employed to debate and capture viewpoints regarding motivations and challenges which service users and carers involved in student social work education may face. The involvement of people who have experience of using social work services and/or of caring for people has implications 
for the nature of knowledge that drives social work education. As educators it is vital to understand, support and develop this involvement. More research is needed to fathom the intricacies of involvement and to detail and explore the processes, by which social work education is delivered in partnership with these key stakeholders. This paper makes no claim to tell the whole story; rather it offers areas for discussion and contemplation which will lead to a greater understanding of ways of improving the learner experience through supporting services user and carer involvement.

\section{Literature review}

Stake holding in education as a paradigm for service user and carer participation is upheld by the GSCC (DoH, 2002). This shift towards service user and carer contribution from that of empowerment and consumerism (1990s) to stake holding and partnership has been noted in the literature (see for example, Levin, 2004; Skilton, 2011). The growing emphasis on greater user involvement and choice reflects progressive policy and practice developments (Webb \& Tossell, 1998). This has implications for education of future social workers and the involvement by service users and carers in their education and the development of their knowledge base. Pawson et al. (2003) stresses that there is not a hierarchy of knowledge which social work students as learners need to assimilate - instead there are sources of knowledge.

These sources include:

1. Organizational knowledge which provides the framework for regulation and governance in social care and includes information drawn from audit, inspection, joint reviews and inquiries;

2. Practitioner knowledge drawn from those working in social care which tends to be personal and context specific, though can be written down in training materials and professional networks;

3. Service user knowledge based on first-hand experience and reflection on intervention. Again this knowledge is often personal and not written down, though there is now an emerging literature based on user led research, and campaigning materials;

4. Research knowledge based on empirical enquiries drawing on a wide range of different methodologies. This form of knowledge is more accessible and available through journals, books and research reports;

5. Policy community knowledge which sets social care in its policy context and where the literature is formulated in policy reports, white papers, think pieces and critiques of policy.

Literature indicates how service users and carers add value to the social work/social care knowledge base (for example, Doel \& Best, 2008; Levin, 2004; Skilton, 2011). Most HEIs have service users and carers involved in some aspect of student social work education, whether this be for example, assessing students work; interviewing prospective students; or telling their story. (Matka et al., 2010; Sadd, 2011; Wallcraft et al., 2012). Some HEIs 'buy in' external organizations to facilitate user and carer involvement, whilst others create and support a group of individuals who have come together to support the relevant programme. An internal service user and carer group, such as that utilised by the participating HEI, is viewed by many HEIs as 
the preferred model because this is seen as facilitating a 'more direct relationship' (Wallcraft $e t$ $a l ., 2012)$. The notion of an 'internal' group refers to a group of individuals who identify themselves as users of social work services, or carers of people who have used or are using social work services and responded to advertisements, placed by the social work team, in local media. This is in contrast to a group pre-formed for other purposes, for example, a carer's support group, which may then include involvement in the education of social work students as an additional activity. However, it is acknowledged within the literature that certain groups remain hard to reach in terms of service user and carer involvement, and participation initiatives have been criticized as lacking attention to diversity (Carr, 2004; Levin, 2004). Hard to reach groups include, for example, children; women who are experiencing violence; and parents who have had children taken into the care of the local authority. The service user and carer group at the participating HEI is heavily 'overpopulated' with carers and people who have used mental health services. This has obvious implications for focus group discussions within that particular area. In the participating HEI, as with most others in England, the most developed areas of participation are regarding interviewing and selection of prospective future social work students (Sadd, 2011; Matka et al., 2010).

It is important that HEIs are clear about the objectives for user and carer involvement in social work education (Webber \& Robinson, 2012). Funding is available to support this involvement paid annually to each HEI regardless of number of students. This can lead to an anomaly. For example, a course with 100 students receives the same amount of funding for service user and carer involvement as does a course for 25 students. Clearly there is more scope to be creative in ways of involvement and to provide appropriate recompense to people for their time with smaller numbers.

The rationale for the research study developed from the literature, which highlights the many benefits brought about by the involvement of people who have experience of using social work services and/or of caring for people. In addition, an imminent change to the regulatory body of social work education in England from the General Social Care Council to The Health Care Professions Council has implications for the focus of social work education. As educators it is vital to understand, support and detail the involvement of external partnerships which exist in HEIs to make clear the perception of the issues as reported by those involved. However, as previously noted, much more research is needed to fathom and record the intricacies of service user and carer involvement in higher education and to detail and explore the processes by which social work education is delivered in partnership with key stakeholders.

\section{Research methodology}

\section{Introduction}

The area for research was identified following discussion with undergraduate students, academic staff and service users and carers who have supported social work education. As a registered social work practitioner and an academic with responsibility for coordinating the involvement of service users and carers, I am committed to developing and supporting service user and carer involvement in extending the knowledge base. Whilst a descriptive approach is interesting, the aim of this project was to explore the motivations of service users and carers involved in student 
social work education and to incorporate the voices of those directly involved. As author of this report I am employed by an English University to coordinate the involvement of people who use services and carers on a new B.A. Social Work degree (commenced 2008). Students need to develop skills of and experience of working with service users and carers prior to commencing their practice placement in the community. The involvement of people who use social work services and carers at the HEI provides a unique opportunity for learners to enhance their skill base in a 'safe' environment. Identifying and developing a group of people to become involved was at times a daunting task, frequent challenges were faced and questions were raised from a number of different stakeholders about the motivation of people who expressed a desire to become involved and the impact on the experience of learners. My focus on service user and carer activities generated initial questions (Silverman, 2005) which were used to develop, plan and carry out a series of focus groups.

\section{Collecting the Data}

The study utilised a qualitative methodology, obtaining data from 16 participants over three focus groups: undergraduate social work students; academic members of staff who had experience of working alongside service users and carers; and service users and carers themselves (see below for participant information). A qualitative methodology was selected as the most appropriate way of enabling participants to discuss the research questions in depth and seek clarification if needed. The focus group discussions concentrated on people's experiences of service user and carer involvement in the programme, what they considered to be prime motivators and challenges faced. With signed consent from participants, the focus groups were audio recorded and later transcribed verbatim. Data was analysed thematically (see below for details). All responses were kept anonymous.

\section{Focus groups}

Given time and financial constraints, it was decided that the most appropriate way of carrying out the research with the relatively small numbers of potential participants, was to run a series of focus groups. The research was a reflective and much planned process (Mathews \& Crawford, 2011), and acknowledged issues of power and inequality on many levels.

Focus groups were utilised as it was recognised that this method allowed a way of obtaining a range of opinions about service user and carer involvement in student social work education in a reliable manner. The appeal of focus groups to many HEI researchers is that they are based on the principle of obtaining rich data (Cousin, 2009). I wanted to obtain a large amount of data and, owing to time and resource constraints, believed the idea of an organised discussion would yield plentiful data, as well as providing an opportunity for participants to clarify their own perspectives. Focus groups offer participants an opportunity to explore and express, or share and compare, their opinions through interactions with other people who have had similar experiences. They also offer an accessible method of data collection for people who may have difficulty with literacy (Owen, 2001) and provide the researcher/moderator with an opportunity to expand and explain any points of confusion. I also ensured that adequate support was available for the all participants following the discussion if so required. 
It can be seen that the focus groups could be seen to be 'naturally occurring' in the way that participants of each group knew each other and were not formed specifically for the purpose of the research. In one way this could be seen to be advantageous to the study as it helped to ensure that participants spoke freely. Conversely, the use of naturally occurring focus groups has been criticized (Morgan, 1997). There may be a tendency for participants who know one another to use 'taken for granted' terminology and experience. However, the benefits of being relaxed and friendly and open to discussions, as well as the familiarity awarded by previously developed relationships, appealed as an option regarding the subject matter. It was decided to keep focus groups relatively small, primarily so that more detailed and comprehensive data would emerge from each participant and also to enable me to manage, appreciate and be familiar with data produced by the discussions.

Initially people were asked to introduce themselves and a brief synopsis of the research project was given. The fact that people were free to go at any time and to withdraw their consent at any time was reiterated. The sessions that took place were wide and varied. They provided direct evidence of similarities and variations of viewpoints between participants. For all three focus groups I ensured questions were available to prompt the discussion if necessary. In practice, however, these were not used, as the discussions flowed fairly easily. The focus groups were relatively unstructured, with the researcher involved in active listening throughout. This enabled identification of any new areas for discussion and investigation, and to be sensitive to the emotional responses of the participants. The focus groups contained what Morgan called 'low moderator-involvement' (1997, p.48). The aim was for a group discussion which would predominately manage itself. The sessions began with a general question, acknowledging the fact that all of the participants had experience of service user and carer involvement in social work education and enquiring how they felt about that. Following an open discussion between participants about this, the discussion moved from motivating factors to challenges, as previously noted prompts were prepared to be used if the conversation lapsed into silence however this was not the case.

\section{Participants}

Focus group 1 consisted of 6 service users and carers who had responded to an open invitation published in a newsletter sent to all service users and carers on the database $(n=38)$ who supported social work education at the participating HEI.

Focus group 2 comprised 4 members of academic staff from the participating institution from a potential group of 8 who have experience of being involved in teaching on undergraduate social work programmes alongside working with service users and carers.

Focus group 3 consisted of 6 second year undergraduate social work students from the HEI who took up a general invitation to all year two $(n=26)$ students to become involved. Year two students were approached only, as year one students were due to commence practice placement during the potential 'window' for the focus group discussion and final year students were already on placement.

\section{Ethical considerations}


Ethical issues attached to developing a project within one's own work place and, in particular, involving students, are many. As an 'in-house' researcher, ensuring that the neutrality of the research from my substantive post was made clear was crucial. Any conflicts of interest were made explicit, transparency of the aims and process was of prime consideration. The dignity; rights; safety; and well-being of participants must be the main aim in any research study. Researchers must not engage in practices which exploit or harm service users (Payne, 2009).

Ethical approval was sought and obtained from the participating HEI. Academic rigor needed to be shown throughout. Full information regarding the project was made available at all times. Information sheets were given and signed consent forms were obtained. All participants were competent to give consent and it was emphasised that involvement in the project would have no bearing on other areas of academic life, for example student assessment or further opportunities for service user and carer paid involvement. Social work code of ethics for research was adhered to throughout the project (BASW, 2012). Seeking informed consent is particularly relevant in social work research with service users and carers as they traditionally have been seen to have no voice in the research process and may acquiesce with perceived authority figures (Mathews \& Crawford, 2011).

\section{Data analysis}

The data obtained from the focus group discussions expressed diverse perspectives about the motivations and challenges of service user and carer involvement. The data was analysed in a 'methodical manner' (Attride-Stirling, 2001, p.386) in order to yield meaningful and useful results. In analysing the focus group transcripts using thematic analysis, and keeping at the forefront the research question: 'What the motivations are of service users and carers and what challenges does such involvement bring?', enabled a methodical and insightful exploration of text to occur. Themes were divided into 'networks...that summarize the main themes constituting a piece of text' (Attride-Stirling, 2001, p.386). This involved starting with basic themes, moving through organising themes and arriving at global themes which allowed both a summary and an interpretation of the data. By utilising such an approach it has been possible to analyse the understanding which participants had of the issue, as opposed to reconciling conflicting definitions of motivations and challenges of involvement. This is a significant point, as a qualified and experienced social worker, I needed to apply a tool of analysis that fitted with the objectives of the research and not purely that of generalized social work practice (empowering, supportive, counselling for example). Two main areas and sub themes were identified.

\section{Theme 1: Motivations of service user and carer involvement}


- The affirmation gained by service users and carers by being involved in student social work education and a feeling of enhancing the learner experience in a unique way;

- Financial recompense;

- Employment opportunities/further education opportunities;

- Desire to shape services for the future;

- To ensure that when current learners go into practice they will use their skills gained from the work with service users and carers in the HEI;

- Have their voices heard by a 'captive' audience/telling their story;

- Opportunities to meet people and socialise.

Theme 2: Challenges of service user and carer involvement

- Lack of diversity in the service user and carer group;

- The reluctance by student social workers, academic staff, and other service users and carers to challenge individual service users and carer perspectives;

- Service users and carers contributions aren't sufficiently evaluated. Difficulty in noting student achievement and linking it to specific elements of the programme;

- Group becomes 'territorial'. Reluctance to expand;

- Oppression/discriminatory attitudes displayed by service users and carers;

- Service Users and carers who are unwell. For example in the group were several people who described themselves as survivors of mental health services, and there have been occasions when their fitness to participate has been questioned;

- Communication between academic staff and service users and carers. Evaluation of process and limited opportunities for involvement;

- Difficulties staff have in terms of attempting to adapt their previous role to the involvement of service users and carers in academia.

\section{Analysis of themes}

Student social workers' learning is integrated with their practice and arises from it. The situated learning develops during the successive stages of social work education. Students need to operate in an environment where they create meaning and learning for themselves (Biggs, 2003). All aspects of the social work programme need to support appropriate student learning and the involvement of service users and carers in this can bridge the gap between theory and practice. Students' learning activities which involve service users and carers help to make personal the meaning that is transmitted by the formal element of teaching by academic staff at the HEI. The deep learning that is necessary to produce effective learning can be attained by constructive alignment of the way that students relate to their learning/teaching environment. The curriculums, the teaching methods, the assessment procedures, the relationship between the teacher and the student as well as the institutional climate are critical components regarding constructive alignment (Biggs, 2003). To this I would add the relationship between students and service users and carers as they are such an integral part of the social work experience both inside and outside the HEI. 
For Teater (2011), social work students need to acquire integrative as well as extended understanding, such as applying counselling skills and carrying out assessments. How much the involvement of service users and carers assists with the critical thinking and skills of analysis needed by social work students is difficult to measure and ascertain. By meeting and communicating with service users and carers as a student social work student, the real life aspects of 'doing' the profession is present. The curriculum is designed in such a way as to align outcomes (for example, an understanding of social work theories) with real life examples of social work intervention from recipients of the same. This concrete experience is consistent with learning styles of students as advocated by learning theorists (Kolb, 1984; Race, 2007). It is this element that the service users and carers perceived as being most motivational for their continued involvement. For example one service user said:

'I think...well we are you know, really a living example for the students. That's what I like, the feeling like we are giving something back'.

When considering findings from this piece of research it is important to note that clearly each individual has different drivers in terms of motivation which arises from their personal circumstances, their personality and their past experiences; this statement applies to service users, students and academics. It is significant however, that within research the voices of service users and carers are seldom heard. Within all focus group discussions a range of competing perspectives were debated.

The main themes to emerge were challenge and motivations around service user and carer involvement. Within these were sub themes; benefits, and an imbalance of power. Power was discussed in terms of being between service users, carers and students and between service users, carers and academic staff. Although in their second year of study and having worked in a variety of placement settings with service users and carers, there were still moments when the students reported being in awe of the service users and carers who were involved in the academic programme.

'I'm scared of saying the wrong thing... what do I say? Am I supposed to know what to say? I'm still learning, I'm new to all this-I don't know what to say!' (Student)

Students felt that service users and carers are in a position of power. They were aware that service users and carers may be asked for judgments on the students' performance, or assessing their work or reading their portfolio. Students commented on the difference they felt between working with service users and carers in the university setting as opposed to encountering them on practice placement.

'Contact with service users and carers on placement was different. I felt that there was a real shift in power - the balance was altered ... when I am in uni with service users and carers I am almost in awe of them and their experiences. They give so much... and yet expect so little in return.... when I am on placement I felt like I was in a position to...ok we'll kind of identify the need here.... phone that service... do that assessment it was like it was up to me to do it'. (Student). 
'On placement I felt in control...ok I can ring up and make a referral but at University I am here more to learn, just by speaking to people and seeing service users around the place helps.'

(Student)

The power imbalance was felt very strongly therefore within the academic environment, although students noted how aspects of service user and carer involvement enhanced their learning, this included case study discussions and listening to people sharing their experiences. Academic staff also made reference directly to power issues. They described how, as much as they recognised the value that service users and carers brought to the learner experience throughout the programme, there were differences in approach and style of teaching and learning as well as level of responsibilities. There was clear demarcation from staff regarding the purpose of the programme.

'Our responsibility is to the students. We can't absolve ourselves from that responsibility. They (service users and carers) contribute to it, they don't have overall responsibility.'

For some academic staff it is a different role in which to see service users and carers. There was recognition that all academics who have had experience of service users and carer involvement in social work education were also qualified and experienced social workers. This raised issues regarding the way service users and carers were viewed. For example, as one academic commented:

'We want to be inclusive, supporting vulnerable people, If people's voices haven't been heard before, they have an opportunity to be heard through their involvement.'

Similarly staff felt that sometimes there was a blurring of how they were perceived by service users and carers for example:

'Sometimes we bridge the divide between social work and academia. This is not problem free. For example if people are unwell. Do we allow service users and carers to carry on when it's not that helpful?'

One of the overarching themes noted by all participants was the friendly and relaxed way service users and carers were involved in student education. One area given emphasis by service users and carers was that they felt welcomed at the HEI and had enjoyed the experience of being involved. Typical comments were:

'I enjoy my role immensely.' (Service user)

'For me I have obtained open and honest friendship from the service user and carer group.' (Carer)

The length of time to establish, enable and maintain service user and carer involvement to take place is immense. Relationships need to be built and trust developed, as well as practical skills developed. For some service users and carers, the practicalities were perceived as a challenge: 
'I would like to see a more formal acknowledgement of our role. At the moment it feels very ad hoc at times.' (Carer)

'Well the training we did initially was good but then that was it. I would like to do more training but it takes time on everyone's part, time and money.' (Service user).

The institutional climate towards participation at the participating HEI is positive and takes the involvement of service users and carers seriously; this is assisted by the provision of funding from the GSCC. Despite this, the payment of service users and carers is a challenge. The infrastructure needs to be better established to ensure reimbursement and payment takes place in a timely and appropriate manner. Service user and carer involvement is still in the relatively early stages of development. However, the positive feedback from service users and carers, academic staff and students provides encouragement for continuing with the process. As one carer commented:

'I love sharing experiences. Students make assumptions and I am really interested in that, they fire me with enthusiasm'.

The benefit of involvement, including the social side for service users and carers was noted by all focus groups.

'I am motivated by feeling that my efforts are appreciated...it's that positive feedback you get from students and staff really.' (Carer)

Students also recognised the social benefits that service users and carers may experience from being part of a group supporting students learning. They felt that a motivator for service users and carers is that it provides an opportunity to meet up with other service users and carers in an environment that was 'outside' the usual settings.

'Within the group there must be aspects of them getting support from each other - even if it wasn't set up as a therapy group there can be support and therapy within that and that is always really useful.' (Student)

Within the focus group discussions, some academics felt that service users and carers motivations were shaped by the affirmation they received from telling their story. This was seen as problematic by some because they questioned whether the service users and carers could move on from that. However, for learners this proved to be the most interesting aspect of work with service users and carers.

A motivating factor for service users and carers, and clearly a benefit to them, were that they believed they were doing useful and worthwhile work and that what they did would make a difference to social workers (and ultimately service users and carers) of the future. This was of particular resonance to people who had not necessarily had a positive experience of social work involvement in the past. For some it was a 'crusade' to ensure that others in similar positions to themselves receive a more appropriate and sympathetic service. For others, the opportunity to influence students' education was the main motivational factor. 
Other service users and carers explained that they felt benefited by the opportunity to earn some money and also to improve their career prospects. For one service user:

'I can use the experience to go on my CV and hopefully lead to paid employment in the future.'

Students see involvement by service users and carers as adding depth to teaching sessions and 'bringing the session alive'. The involvement of service users and carers enhances the student learning experience by creating an environment where existing prejudices are challenged. For example, one student noted:

'We need the reality... we don't want their narrative wrapped up in cotton wool and spoon fed to us.'

As noted previously, the group of service users and carers at the participating HEI tend to be adults who have used mental health services or carers. The lack of diversity of the service user and carer group was seen as a challenge by students and not reflective of the general population.

'The service users and carers we have been in touch with here (participating HEI) all seem to be older - they probably have more time.' (Student)

Some students saw a challenge for service users and carers as being the relevance of someone's experience. For example, how recent their experience was. Some students felt that they lacked currency whereas for others there was an element of 'historical' interest.

If someone came along and said well...I was a carer 20 or so years ago.... we can learn from that we can see how things have changed.' (Student)

The development of confidence and skills occurs throughout the course for student social workers. It was noted by students that they had dual responsibilities: to learn and develop skills from the involvement of service users and carers; and to challenge anti-oppressive comments which may be made by service users or carers. They felt that this would have been difficult earlier on in their education. As one student noted:

'As first years it would be hard, but as we get on then it would be easier. It's about dealing with it in an appropriate manner.'

'There is that fear isn't there in the first year. I felt it was absolutely frightening speaking to service users and carers. It's a real learning curve I think it's invaluable now, but at the time.......' (Student)

How much of this development can be attributed to service user and carer involvement is difficult to evaluate. Students gave examples of how they initially came into contact with service users and carers. They saw themselves that it was a progression, and all felt that it was a part of the social work programme that they enjoyed most. Students felt that service users and carers motivations were philanthropic; that they wanted to help future generations of service users and 
carers, not knowing who they may help. For some students there was a concern it was a one sided relationship.

'It's almost clinical isn't it? We hear their stories and then go away - that feeling we are not giving everything back except a thank you and a wave as we go off to our next lecture.'

(Student)

The motivation for involvement by service users and carers of having their voices heard was not without its difficulties. Academic staff noted challenges and raised concerns regarding the impact on service users and carers if their opinions and perspectives were disagreed with. Staff recognised that the opinion and perspective of service users and cares was just one perspective. Service users and carers are not a homogenous group and it is important that students hear a variety of perspectives to allow a balanced discussion of key issues to take place. Academic staff was mindful of the impact on individuals of being questioned or challenged on some of the points they were making.

'If we challenge that voice we wonder if we are perhaps having a negative effect on them and they may have already been badly treated without us contributing to that....we will listen to their viewpoint and then we turn round and say 'well you have to be careful'. If we have a problem saying it then it's no wonder the students have a problem saying that'.

A challenge for involvement was that however well supported and prepared service users and carers are to participate in a teaching session, what they say at the time may not be acceptable. What happens, for example, if the service user or carer displays racist or homophobic views? The challenge for staff is to sensitively manage that situation, however this is not easy. Equality and diversity training is made available for all service users and carers, however there is obviously no way of knowing what individuals will say to learners when they work with them.

One example discussed in the focus group was an occasion when service users and carers suggested to students that parents of children with disabilities are chosen by God. This may be the view of some people; however by letting that comments go unquestioned in a session may give the impression to students that academic staff agreed with it. Learners need to be supported in developing skills of analysis and critical thinking. It is important that students understand the view of service users and carers is just one perspective amongst many.

It was felt that service users and carers involvement needed a higher level of evaluation than that currently employed. Like many other programmes, evaluation of service user and carer involvement is patchy. It is a complex area to unpick and is clearly an area which needs further research.

\section{Limitations}

- This is a small scale study which focuses attention on one particular HEI and those associated with service user and carer participation in it.

- There may be potential for response bias. For example, participants had a 'vested' interest in focusing on the positive aspects of the role. 
- The service users and carers who participated in the focus groups were members of the wider group which support social work student education at the participating HEI. There is an acknowledgement that the group lacks diversity, which will impact on the range and variations of responses.

- The strength of the study is in its existence. Service user and carer involvement in social work education is still a relatively new phenomenon. The exploration of motivations and challenges adds to the developing body of knowledge which surrounds this important aspect of social work education.

\section{Conclusions and recommendations for enhancement of practice}

This paper has examined service user and carer motivations and challenges and how they enhance practice and ultimately the student experience. By exploring motivations and challenges of service users and carers, as an educator, I hoped to clarify elements of learning best supported by users of social care services and their carers. In conclusion, it may be seen that for service users and carers, some motivating factors may be intensely personal, others career related, others financial. There must therefore be room in the involvement of service users and carers to express their viewpoint and to influence the future generation of social work practitioners. The recognition of the rights of service users and carers to become involved which is required by the GSCC needs to be approached from a person-centred position. Service user and carer involvement in social work education needs to be further developed with attention paid to power relationships (Levin, 2004). Service users and carers need to be involved in designing research to contribute to the evidence base surrounding service user and carer involvement in social work education. This would substantially enhance practice by making evident what is effective in guiding and shaping student learning. Currently there is a dearth of information regarding the impact service user and carer involvement is having in the medium to long term. Despite the differences in service user and carer motivations, student satisfaction is high. It is important to note that service user and carer involvement in student education is an ongoing process and not a one off event. This point needs to be expanded upon to students by educators and is linked with their professional knowledge. As qualified social work practitioners there is still much to learn and their journey has just begun. The challenge remains for evaluation of service user and carer involvement and reflection on the delivery of such, which needs to be carried out in a systematic and rigorous manner. In a similar vein, a promotion of feedback strategies from the perspective of students is needed. Finally, an awareness of the inherent power imbalance needs to be acknowledged to provide an open and honest working relationship which will have positive effects in relation to the student experience. Included within this is the power imbalance between service users themselves. Within any group there are possibilities of oppression and discrimination, groups of people who support student education are no exception.

\section{References}

Ager, W., Dow, J. and Gee, M. (2005) 'Grassroots networks: a model for promoting the influence of service users and carers in social work education.' Social Work Education. 24 (4): 467-476. 
Attride-Stirling, J. (2001) 'Thematic networks: an analytic tool for qualitative research.' Qualitative Research. 1 (3): 385-405.

BASW (2012) British Association of Social Workers Code of Ethics. Available online: http://www.basw.co.uk/codeofethics/ (accessed 29th May 2012).

Biggs, J. (2003) Teaching for Quality Learning at University. Second edition. Buckingham: Open University Press.

Carr, S. (2004) Has Service User Participation Made a Difference to Social Care Services? Position Paper No 3. London: Social Care Institute for Excellence. Available online: http://www.scie.org.uk/publications/positionpapers/pp03.asp (accessed 29th May 2012).

Cousin, G. (2009) Researching Learning in Higher Education: An Introduction to Contemporary Methods and Approaches. London: Routledge.

Department of Health (DoH) (2002) Requirements for Social Work Training. London: Department of Health.

Doel, M. and Best, L. (2008) Experiencing Social Work Learning from Service Users. London: Sage.

Kolb, D. A. (1984) Experiential Learning: Experience as the Source of Learning and Development. New Jersey: Prentice-Hall.

Levin, E. (2004) Involving Service Users and Carers in Social Work Education. London: Social Care Institute for Excellence.

Mathews, I. and Crawford, K. (2011) Evidence-based Practice in Social Work. Exeter: Learning Matters.

Matka, E., River, D., Littlechild, R. and Powell, T. (2010) 'Involving service users and carers in admissions for courses in social work and clinical psychology: cross-disciplinary comparison of practices at the University of Birmingham'. British Journal of Social Work. 40 (7): 2137-2154.

Morgan, D. (1997) Focus Groups as Qualitative Research. London: Sage.

Owen, S. (2001). 'The practical, methodological and ethical dilemmas of conducting focus groups with vulnerable clients'. Journal of Advanced Nursing. 36 (5): 652-658.

Pawson, R., Boaz, A., Grayson, L., Long, A. and Barnes, C. (2003) Types and Quality of Knowledge in Social Care. SCIE Knowledge Review. London: Social Care Institute for Excellence. 
Payne, M. (2009) Doing literature Searches and Reviews. In Adams, R., Dominelli, L. and Payne, M. (eds) Practicing Social Work in a Complex World. Second edition. Basingstoke: Palgrave Macmillan.

Race, P. (2007) The Lecturer's Toolkit: A Practical Guide to Assessment, Learning and Teaching. Third edition. Abingdon: Routledge.

Sadd, J. (2011) 'We are more than our story'; Service User and Carer Participation in Social Work Education. London: Social Care Institute for Excellence.

Silverman, D. (2005) Doing Qualitative Research. Second edition. London: Sage.

Skilton, C. J. (2011) 'Involving experts by experience in assessing student's readiness to practise: the value of experiential learning in student reflection and preparation for practice'. Social Work Education. 30 (3): 299-311.

Teater, B. A. (2011) 'Maximizing student learning: a case example of applying teaching and learning theory in social work education. Social Work Education. 30 (5): 571-585.

Wallcraft, J., Fleischmann, P. and Schofield, P. (2012) The Involvement of Service Users and Carers in Social Work Education: A Practice Benchmarking Study. London: Social Care Institute for Excellence.

Webb, R. and Tossell, D. (1998) Social Issues for Carers: Towards Positive Practice. Second edition. London: Hodder Arnold.

Webber, M. and Robinson, K. (2012) 'The meaningful involvement of service users and carers in advanced-level post-qualifying social work education: a qualitative study'. British Journal of Social Work. 42: 1256-1274.

\section{About the author}

Valerie Gant is service user/carer coordinator and social work tutor on the BA (Hons) Social Work at Edge Hill University, Ormskirk, Lancashire.

Email: Valerie.Gant@edgehill.ac.uk 